\title{
PERUBAHAN KADAR DEBU UDARA SAAT "CAR FREE DAY" DI SURABAYA TAHUN 2016
}

Safitri Praneliani, Khambali, Marlik

\begin{abstract}
Level of dust particles $\left(\mathrm{PM}_{10}\right)$ in Surabaya is the highest in East Java because of the increasing number of motor vehicles. To reduce exhaust emissions of motor vehicles which produce dust particles $\left(\mathrm{PM}_{10}\right)$, the government of Indonesia has launched the Langit Biru / Blue Sky program with Car Free Day as one of its programs. This study aims to determine differences of air dust level at Car Free Day and non-Car Free Day in Darmo street, Surabaya.

The design of research is analytic research. The research object was along Darmostreet. The data were collected by using survey with cross sectional approach and the data were proceeded the form of editing, tabulation and textular.

The results of the study shows that the average temperature, humidity, wind speed and the amount of dust in the air during the Car Free Day were $28.78{ }^{\circ} \mathrm{C}, 76.22 \%, 1.48 \mathrm{~m} / \mathrm{s}$ and $135 \mathrm{mg} / \mathrm{Nm}^{3}$ respectively and in the absence of Car Free Day were $28.55{ }^{\circ} \mathrm{C}, 77.40 \%, 1.13 \mathrm{~m} / \mathrm{s}$ and $388.16 \mathrm{mg} / \mathrm{Nm}^{3}$ respectively.

There was significant difference in the dust level $\left(\mathrm{PM}_{10}\right)$ in the air during the Car Free Day and Non Car Free Day. It is advisable for the government to consider changing the technical implementation of the Car Free Day such as adding more day.
\end{abstract}

Keywords

: Dust particles $\left(P M_{10}\right)$, Car Free Day, Air Pollution

\section{PENDAHULUAN}

Pencemaran udara sudah menjadi masalah serius di kota besar di dunia (Indah, 2014). Krisnaya \& Bedi (1986) dalam Hermawan (2011) mengemukakan kualitas lingkungan udara di perkotaan cenderung mengalami penurunan terutama disebabkan oleh aktivitas transportasi. Jumlah kendaraan di Indonesia sebagai penghasil emisi gas rumah kaca sangat tinggi. Hingga tahun 2012 menurut data Kantor Kepolisian Republik Indonesia, jumlah kendaraan di Indonesia mencapai 76.381.183. Semakin banyaknya jumlah kendaraan bermotor menjadi penyebab meningkatnya pemanasan global.

Debu partikulat ini juga terutama dihasilkan dari emisi gas buang kendaraan. Sekitar $50 \%-60 \%$ dari partikel melayang merupakan debu berdiameter $10 \mu \mathrm{m}$ atau dikenal dengan Particulate Matter 10 atau yang disingkat $\mathrm{PM}_{10}$. Debu $\mathrm{PM}_{10}$ ini bersifat sangat mudah terhirup dan masuk ke dalam paru-paru, sehingga $\mathrm{PM}_{10}$ dikategorikan sebagai Respirable Particulate Matter (RPM). Akibatnya akan mengganggu sistem pernafasan bagian atas maupun bagian bawah (alveoli).

Menurut data Badan Lingkungan Hidup (2011) dalam Aisyiah (2014) Kadar partikel debu $\left(\mathrm{PM}_{10}\right)$ di Kota Surabaya menempati urutan tertinggi di Jawa Timur, dibandingkan dengan kadar $\mathrm{O}_{3}, \mathrm{SO}_{2}$, dan $\mathrm{CO}_{2}$. Konsentrasi rata - rata partikel debu $\left(\mathrm{PM}_{10}\right)$ tahun 2011 sebesar $2,168 \mathrm{mg} / \mathrm{m}^{3}$, sehingga melebihi baku mutu udara ambien. Tahun 2014 konsentrasi rata - rata partikel debu $\left(\mathrm{PM}_{10}\right)$ adalah 0,262 , sehingga melebihi baku mutu udara ambien. Untuk mengurangi emisi gas buang kendaraan bermotor yang menghasilkan partikel debu $\left(\mathrm{PM}_{10}\right)$, Pemerintah Indonesia melalui KepMen LH
No.15/1996 telah mencanangkan program Langit Biru. Program langit biru adalah suatu program pengendalian pencemaran udara dari kegiatan sumber bergerak dan tidak bergerak. Di dalam program tersebut terdapat beberapa program sebagai pendukung pencegahan pencemaran udara, yaitu pemantauan uji emisi, pemantauan kinerja lalu lintas, pemantauan kualitas bahan bakar minyak di Stasiun Pengisian Bahan Bakar Umum (SPBU), pemantauan kualitas udara jalan raya (roadside monitoring) untuk parameter $\mathrm{SO}_{2}, \mathrm{CO}$, $\mathrm{NO}_{2}, \mathrm{HC}, \mathrm{O}_{3}, \mathrm{PM}_{10}$, serta program Car Free Day atau yang disingkat CFD.

Program CFD di Surabaya telah dimulai pada tahun 2008 di sepanjang Jalan Raya Darmo. Program ini dinilai mampu mendukung program langit biru. Berdasarkan hasil penelitian Nicolaus Kanaf (2010) yang berjudul "Efisiensi Program Car Free Day Terhadap Penurunan Emisi Karbon" menyatakan bahwa program CFD di Surabaya berhasil mereduksi emisi $\mathrm{CO}_{2}$ sebesar $21,56 \%$. Sedangkan konsentrasi $\mathrm{CO}_{2}$ pada udara ambien turun sebesar $91,35 \%$.

Penelitian ini bertujuan untuk mengukur suhu, kelembaban dan kecepatan angin, mengukur kadar partikel debu udara saat CFD dan tidak CFD di Jalan Raya Darmo Surabaya, menganalisis perbedaan kadar partikel debu udara saat CFD dan tidak CFD di Jalan Raya Darmo Surabaya.

\section{METODE PENELITIAN}

Jenis penelitian ini bersifat analitik, sedangkan studi yang digunakan adalah cross sectional. Obyek dalam penelitian ini adalah sepanjang lokasi CFD, yaitu mulai dari perempatan Jalan Diponegoro sampai perempatan Jalan Dr. Sutomo dengan titik pengambilan sampel sebanyak 3 titik. Teknik pengumpulan data pada penelitian ini 
dilakukan dengan pengukuran suhu, kelembaban dan kecepatan angin. Selanjutnya dilakukan pengukuran kadar debu udara dengan alat High Volume Dust Sampler (HVDS). Analisis data yang digunakan dalam penelitian ini adalah dengan menggunakan $u j i \mathrm{t}$ independent sampel test. Kriteria Penolakan Hipotesis adalah $\mathrm{P}<\alpha$ dengan hipotesis Ada perbedaan yang signifikan antara kadar debu saat Car Free Day dan Tidak Car Free Day.

\section{HASIL PENELITIAN DAN PEMBAHASAN}

Berdasarkan hasil pengukuran rerata suhu, kelembaban dan kecepatan angin saat CFD ( $\mathrm{Car}$ Free Day) adalah sebesar $28,78{ }^{\circ} \mathrm{C}, 76,22 \%, 1,48$ $\mathrm{m} / \mathrm{s}$. sedangkan pada saat NCFD (Non Car Free Day) rerata suhu, kelembaban dan kecepatan angin adalah $28,55{ }^{\circ} \mathrm{C}, 77,40 \%$ dan $1,13 \mathrm{~m} / \mathrm{s}$. Rerata kadar debu saat CFD adalah minggu ke-1 sebesar $134,66 \mu \mathrm{g} / \mathrm{Nm}^{3}$, sedangkan pada minggu ke-2 $133,33 \mu \mathrm{g} / \mathrm{Nm}^{3}$, dan minggu $\mathrm{ke}-3135 \mu \mathrm{g} / \mathrm{Nm}^{3}$. Pada saat NCFD rerata kadar debu adalah minggu pertama pada hari Senin sebesar $399 \mu \mathrm{g} / \mathrm{Nm}^{3}$, pada hari Jumat $373,33 \mu \mathrm{g} / \mathrm{Nm}^{3}$, minggu kedua hari Senin 399,66 $\mu \mathrm{g} / \mathrm{Nm}^{3}$, hari Jumat sebesar 375 $\mu \mathrm{g} / \mathrm{Nm}^{3}$, serta pada minggu ketiga hari Senin $399,66 \mu \mathrm{g} / \mathrm{Nm}^{3}$ dan hari Jumat $382,33 \mu \mathrm{g} / \mathrm{Nm}^{3}$. Hal ini disebabkan karena pada Jalan Darmo terdapat beberapa jalan putar balik (U-turn) yang menyebabkan terjadinya antrian kendaraan dan menyebabkan kemacetan.

Hasil uji beda kadar debu dengan $a=0,05$ maka didapatkan hasil $p=0,000<0,05$, sehingga Ho ditolak yang berarti terdapat perbedaan yang signifikan kadar debu pada saat Car Free Day dan Non Car Free Day. Kadar debu di udara adalah sebesar 134,66 $\mu \mathrm{g} / \mathrm{Nm}^{3}$ dan saat NCFD kadar debu adalah $399 \mu \mathrm{g} / \mathrm{Nm}^{3}$. Ini berarti terjadi peningkatan kadar debu sebesar 264 atau pada hari kerja jumlah debu total yang terdeteksi menjadi 3 kali lebih besar dibandingkan dengan pada saat pelaksanaan CFD. Hal ini dapat diartikan bahwa program CFD yang diadakan oleh Pemerintah Kota Surabaya telah berhasil dilaksanakan karena jumlah kadar debu yang dihasilkan pada saat NCFD masih diatas ambang batas yang ditentukan yaitu sebesar $150 \mu \mathrm{g} / \mathrm{Nm}^{3}$. Selain program CFD, kecepatan angin, suhu udara dan kelembaban udara adalah bagian dari parameter meteorologi yang dapat mempengaruhi konsentrasi gas pencemar di udara (Neigburger, 1995 dalam Istantinova,dkk, 2012).

Semakin tinggi suhu maka partikel debu yang ada di udara semakin tinggi. Hal ini disebabkan karena di udara yang suhunya terlalu tinggi mengandung uap air yang rendah, maka partikel debu yang relatif kecil akan terus melayang karena tidak ada uap air yang akan membawa partekel tersebut jatuh ke tanah. Partikel ini akan turun kembali ke tanah jika kelembaban di udara relatif tinggi, karena partikel akan terbawa uap air yang ada di udara dan akan jatuh akibat gaya gravitasi. Namun, partikel debu yang kecil tetap berada di udara. Debu yang mengendap dapat mengandung proporsi partikel lebih dari pada yang ada di udara.

Kondisi ini juga berlaku terhadap partikel debu di udara. Semakin tinggi suhu maka partikel debu yang ada di udara semakin tinggi. Hal ini disebabkan karena di udara yang suhunya terlalu tinggi mengandung uap air yang rendah, maka partikel debu yang relatif kecil akan terus melayang karena tidak ada uap air yang akan membawa partekel tersebut jatuh ke tanah. Partikel debu melayang (Suspended Particulate Matter atau SPM) adalah campuran dari bermacam-macam senyawa organik maupun anorganik di udara dengan diameter yang sangat halus antara $<1-500$ mikron. Partikulat ini selalu ada di udara dalam waktu lama terutama di musim kemarau dan masuk ke dalam tubuh melalui paru - paru (Suyono, 2014). Partikel dengan diameter lebih besar dari 2,5 $\mu \mathrm{m}$, dengan sumber emisi dari proses mekanis, digolongkan sebagai partikel kasar. Biasanya berada di udara ambien karena adanya erosi angin yang mengangkat debu tanah naik ke udara (Lestari,P.,et al, 2002 dalam Gertrudis, 2010).

Konsentrasi debu dalam suatu lingkungan juga tergantung pada jumlah pohon. Menurut hasil penelitian Inayah (2010) yang berjudul "Studi Kandungan $\mathrm{Pb}$ dan Kadar Debu Pada Daun Angsana (Pterocarpus indicus) dan Rumput Gajah Mini (Axonopus.sp) Di Pusat kota Tangerang" kandungan Debu pada daun angsana (5,25 - 2,63 $\mu \mathrm{g} / \mathrm{g}$ pada bulan Maret $2009 ; 2,7-4,8 \mu \mathrm{g} / \mathrm{g}$ pada bulan April 2009) dan rumput Gajah Mini (1,06 $0,16 \mu \mathrm{g} / \mathrm{g}$ pada bulan Maret $2009 ; 2,1-3,1 \mu \mathrm{g} / \mathrm{g}$ pada bulan April 2009) dapat disimpulkan bahwa Pterocarpus indicus dan Axonopus.sp mampu menyerap $\mathrm{Pb}$ dan debu. Tanaman yang mendominasi pada taman jalur hijau Jalan Raya Darmo adalah tanaman angsana (Pterocarpus indicus). Semakin banyak pohon, maka semakin rendah konsentrasinya. Hal ini disebabkan karena debu terserap dan terjerap secara intensif oleh jumlah pohon yang banyak. Konsentrasi debu di bawah tajuk pohon lebih rendah daripada konsentrasi debu di luar tajuk pohon pada lingkungan yang jumlah pohonnya banyak. Sebaliknya konsentrasi debu tertinggi pada lingkungan dengan sedikit pohon terdapat di tempat pohon tersebut berada (Nurjazuli, 2010).

Menurut Arwini (2014) dalam penelitian yang berjudul "Analisis Dampak Pelaksanaan Car Free Day Di Kota Denpasar (Studi Kasus: Jalan Raya Puputan Niti Mandala Renon Denpasar)" Dampak pelaksanaaan CFD secara umum berdasarkan lingkup wilayah dapat dibedakan menjadi 3 yaitu dampak lokal, dampak regional dan dampak global. Dampak lokal adalah dampak pelaksanaan CFD terhadap wilayah di area lokal tempat pelaksanaan CFD. Dampak lokal ini misalnya adalah terjadi penurunan pencemaran udara secara langsung di wilayah pelaksanaan CFD. Dampak CFD secara global terjadi bila CFD dilakukan dibanyak 
tempat sehingga dampak yang dihasilkan semakin besar dan dampak yang ditimbulkan akan semakin luas. Dampak yang diakibatkan oleh pelaksanaan CFD secara global misalnya adalah berkurangnya meningkatnya kualitas udara menjadi lebih baik. Dengan kualitas udara yang lebih baik maka kesehatan manusia dan makhluk hidup lainpun akan menjadi lebih baik. Sedangkan bila dilihat dari jangka waktu dampak maka dapat dibedakan menjadi dampak yang ditimbulkan dalam jangka waktu pendek, dalam jangka waktu menengah dan dalam jangka waktu panjang.

\section{KESIMPULAN}

1. Hasil rerata kadar debu saat Car Free Day sebesar $1,34 \mathrm{mg} / \mathrm{m}^{3}$ sedangkan pada saat Non Car Free Day rerata kadar debu sebesar $3,88 \mathrm{mg} / \mathrm{m}^{3}$.

2. Ada perbedaan kadar debu saat Car Free Day dan tidak Car Free Day yang signifikan.

\section{SARAN}

1. Bagi Pemerintah Kota Surabaya Sebaiknya Pemerintah Kota Surabaya dapat menambah beberapa titik jalan serta

\section{DAFTAR PUSTAKA}

Aisyiah, Kurniasari, dkk. 2014. Pemodelan Konsentrasi Partikel Debu (PM10) pada Pencemaran Udara di Kota Surabaya dengan Metode Geographically-Temporally Weighted Regression. Jurnal Sains Dan Seni Pomits. Vol.2, No.1

Arwini, Ni Putu Decy. 2014. Analisis Dampak Pelaksanaan Car Free Day Di Kota Denpasar (Studi Kasus: Jalan Raya Puputan Niti Mandala Renon Denpasar). http://ojs.unud.ac.id/index.php/jsn/article/ view/11979, diakses Senin 4 Juli 2016

Badan Lingkungan hidup. 2011. Laporan Status Lingkungan Hidup Provinsi Jawa Timur Tahun 2011. http://blh.jatimprov.go.id, diakses Selasa 9 Februari 2016

Djuraidah, Anik. 2006. Optimasi Penentuan Lokasi Stasiun Pemantau Kualitas Udara Ambien Di Kota Surabaya. http://journal.ipb.ac.id/ index.php/ statistika/ article/viewFile/5449/4017, diakses Senin 11 Januari 2016

Gertrudis. 2010. Hubungan Antara Kadar partikulat $\left(P M_{10}\right)$ Udara rumah tinggal dengan kejadian ISPA pada balita di sekitar pabrik semen PT. Indocement, Citeureup Tahun 2010. http:///ontar.ui.ac.id/, diakses Senin 14 Desember 2015

Hermawan, Rachmad. 2011. Pengaruh Jumlah Baris Tanaman Jalur Hijau Jalan Dalam Mereduksi Partikel Timbal (Pb) Dari Emisi Kendaraan Bermotor (Studi Kasus Jalur produksi karbon dioksida, belerang dioksida, nitrogen dioksida, timbal, partikel debu dan oksidan yang secara langsung akan berakibat pada

penambahan hari untuk kegiatan Car Free Day agar $\mathrm{CO}, \mathrm{CO}_{2}$, $\mathrm{NO}$, karbon, hidrokarbon, aldehide dan partikel yang dihasilkan kendaraan bermotor dapat berkurang

2. Bagi peneliti lain

a. Disarankan menambah titik pengambilan sampel.

b. Pengukuran sebaiknya dilakukan pada musim kemarau dan musim hujan, untuk memperoleh konsentrasi bahan pencemar ratarata.

c. Pengukuran pada saat NCFD dapat menambah waktu dan hari pengambilan sampel.

3. Bagi Masyarakat

a. Turut serta mendukung program CFD yang telah dilaksanakan agar lebih efektif dalam mengendalikan kualitas lingkungan khususnya udara.

Hijau Acacia Mangium Jalan Tol Jagorawi). http://lbprastdp.staff.ipb.ac.id/files/2012/0 3/rahmad1.pdf, diakses Senin 14 Desember 2015

Inayah, Siti Nihayatul. 2010. Studi Kandungan Pb dan Kadar Debu Pada Daun Angsana (Pterocarpus indicus) dan Rumput Gajah Mini (Axonopus.sp) Di Pusat kota Tangerang. http :// repository.uinjkt.ac.id /dspace $\frac{\text { /bitstream } / 12345}{1234}$ 6789/21359/1/SITI\%20NIHAYATUL\%20IN AYAH-FST.pdf, diakses Senin 4 Juli 2016

Indah, Fitriana. 2014. Analisis Tingkat Pencemaran Udara Pada Kawasan Pemukiman Kota Makassar.

http://repository.unhas.ac.id/bitstream/ha ndle/

123456789/9588/Fitriana\%20Indah\%20Up load\%20Unhas.pdf?sequence $=1$, diakses Senin 14 Desember 2015

Istantinova, Dea Budi, dkk. 2012. Pengaruh Kecepatan Angin, Kelembaban Dan Suhu Udara Terhadap Konsentrasi Gas Pencemar Sulfur Dioksida (So2) Dalam Udara Ambien Di Sekitar Pt. Inti General Yaja Steel Semarang. http://ejournals1.undip.ac.id/index.php/tlin gkungan/article/viewFile/2673/2666, diakses Senin 4 Juli 2016

Kanaf, Nicolaus., \& Razif. 2010. Efisiensi Program Car Free Day Terhadap Penurunan Emisi Karbon. http://digilib.its.ac.id/public/ITSUndergraduate-14082-paperpdf.pdf, diakses Senin 14 Desember 2015 
Keputusan Menteri Lingkungan Hidup No. No. 15 Tahun 1996 Tentang Program Langit Biru.

Kestina, Ayu Tri H. 2013. Hubungan Antara Kadar Debu Ambien dengan Keluhan Subyektif Pekerja Bagian Penambangan Bahan Baku Semen PT. Semen Indonesia.

Notoatmodjo, Soekidjo. 2010. Metodologi Penelitian Kesehatan. Jakarta. PT. Rineka Cipta.

Nurjazuli, dkk. 2010. Analisis Perbedaan Kapasitas Fungsi Paru Pada Pedagang Kaki Lima Berdasarkan Kadar Debu Tatal Di Jalan Nasional Kota Semarang. http://jurnal.unimus.ac.id/index.php/jkmi/ article/view/144/124, diakses Senin 4 Juli 2016

Peraturan Pemerintah Kota Surabaya No. 24 Tahun 2014 tentang Perubahan Atas Peraturan Walikota Surabaya Nomor 74 Tahun 2013 Tentang Penyelenggaraan Hari Bebas Kendaraan Bermotor.

Peraturan Pemerintah Republik Indonesia No. 41 Tahun 1999 Tentang Pengendalian Pencemaran Udara

Peraturan Walikota Surabaya Nomor 74 Tahun 2013 Tentang Penyelenggaraan Hari Bebas Kendaraan Bermotor 